\title{
Developing a Network protocol: nurse-led weaning from ventilation
}

Paul Fulbrook RN; PhD, MSc, PGDE, BSc (Hons), DPSN Clinical Reader in Critical Care, Centre for Practice Development, Institute of Health \& Community Studies, Bournemouth University, UK Nalini Delaney RN Staff Nurse, ICU, North Hants Hospitals NHS Trust, Basingstoke, UK Joanne Rigby RN, Senior Sister, General ICU, Southampton University Hospital, Southampton, UK Anne Sowden RN, Sister, Itchener Ward, Royal West Sussex NHS Trust, Chichester, UK Marilyn Trevett RN BSc(Hons), DPSN, Acting Senior Nurse Manager, ICU/HDU, Poole Hospitals NHS Trust, Poole, UK Louise Turner RN, Senior Staff Nurse, Maiden Castle Unit, West Dorset Hospitals NHS Trust, Dorchester, UK * Alison Whittam RN, Senior Sister, Cardiothoracic ICU, Southampton University Hospital, Southampton, UK.

E-mail: fulbrook@bournemouth.ac.uk

Key words: Critical care network nurse-led nursing protocols ventilation weaning

\section{SUMMARY}

* In modern health care there is an expectation that all practice is evidence-based.

* One area that has received a lot of attention with regard to its evidence base is weaning from mechanical ventilation.

* There is a growing body of evidence that suggests that protocol-driven weaning from ventilation improves patient outcomes.

* In many intensive care units, nurses have taken a lead role in weaning patients from ventilation.

* This paper describes a nurse-led weaning protocol that was developed by a critical care network.

* The protocol is explained, and the charts that were developed to support it are presented.

* The protocol is currently being implemented in four different intensive care units, which are being audited during the first six months of its use.

* The audit processes of data collection and analysis are also described.

\section{INTRODUCTION}

In the current climate of health care in the UK, Government directives (Department of Health (DoH), 1996; 1997; 1998) have made it imperative that those working in critical care environments examine their practice to ensure that it is evidence-based and of a high quality. The importance of knowledge-based practice is constantly emphasised, with the expectation that evidence-based decision-making and practice are at the heart of all health care (Bonell, 1999). One area that has received a lot of attention in this context is weaning from ventilation. This paper presents a nurse-led weaning from ventilation protocol. It is currently being implemented in four intensive care units (ICUs).

\section{BACKGROUND}

The Central Southern Critical Care Network Weaning Protocol was developed by a project group of English intensive care nurses. It is based on the Salisbury nurse-led weaning protocol (Lowe et al., 2001). Overseen by the Modernisation Agency for Critical Care, critical care networks are geographically-linked clusters of National Health Service (NHS) Trust (acute hospital) critical care representatives: doctors, nurses and allied health professionals. The purpose of these groups is to develop a collaborative approach between acute Trusts for delivering the critical care agenda as set out in Comprehensive Critical Care (DoH, 2000).

'The ultimate goal of the [modernisation] Programme [for critical care] is to improve access, experience and outcomes for patients with potential or actual need for critical care based on the severity of their illness and not where their care is delivered' (NHS Modernisation Agency, 2004).

Networks take responsibility for the planning and implementation of improvement projects. One of their aims is to draw together teams from clinical and managerial environments so that everyone in the network is working together to develop shared ways of working that have the patient at their centre.

The Central Southern Critical Care Network is based on the south coast of England, and comprises ten acute hospitals. A subgroup of senior critical care nurses meets regularly to identify and facilitate the implementation of improvement and practice development projects. This group identified nurse-led weaning from ventilation as one of the priority areas for action.

\section{Weaning from ventilation}

Weaning is defined as the process of gradually reducing mechanical ventilatory support as the patient's own respiratory system recovers from disease (Keen, 2000). The length of time required for successful weaning is usually related to the underlying disease process and the patient's state of health prior to mechanical ventilation (Esteban et al., 1995; Cronin, 1997). Successful weaning from ventilatory support is the ultimate goal for all those involved in the care of mechanically ventilated patients in ICUs. Although this may be a straightforward process for many patients, 
a significant minority requires more complex and time-consuming approaches.

Weaning a patient from mechanical ventilation is a process, not an event. Although the majority of patients (around $70-80 \%$ ) are weaned rapidly and easily from mechanical ventilation, around $20-30 \%$ may require more gradual withdrawal (Vassilakopoulos et al., 1996). This period of transition from total ventilatory support to spontaneous breathing can absorb $40-60 \%$ of the total period of mechanical ventilation support (Esteban et al., 1994). Accordingly, both morbidity and mortality are likely to be higher in the group that is less easy to wean (Mancebo, 1996), and it is clearly desirable to minimise the weaning period.

Many advances have been made regarding the optimal methods of weaning ventilatory support and liberating patients from the ventilator. These efforts are important because mechanical ventilation is associated with considerable morbidity, mortality and costs. However, the premature discontinuation of mechanical ventilation can also contribute to the incidence of failed extubation, nosocomial pneumonia or increased mortality.

\section{Weaning protocols}

There are several well-documented benefits of timely weaning from ventilation. A growing body of evidence suggests that when a protocol is used the process is more efficient (for example, Ely et al. 2001), less costly, and may reduce the duration of mechanical ventilation and length of stay (Henneman et al., 2002). This is highly relevant in an area where long-term mechanical ventilation (24 hours or more) is expensive, requiring high staffing ratios (Knebel, 1991) and may be associated with mortality rates of 3040\% (Scheinhorn et al., 1994).

The documented physical and psychological benefits of timely weaning for patients include:

* Reduced risk of post-operative complications, for example chest infection and airway trauma;

* Early return to independence and resumption of normal daily activities;

* Promotion of expedient recovery and rehabilitation;

* Regaining a normal sleep pattern;

* $\quad$ Reduced level of stress for both patients and their families.

\section{Nurse-led weaning}

Traditionally, weaning patients from the mechanical ventilator and extubation were the responsibility of medical staff. However, in many ICUs, nurses have expanded their roles, with more experienced nurses taking a lead part in the process. This expansion of role has been variable, determined largely by local need and the support of medical colleagues. When the Scope of Professional Practice (UKCC, 1992) was introduced in the UK, nurses were liberated from the restraints that had previously limited their practice. However, it also brought with it new levels of responsibility and accountability. (See 'Legal Issues' below). What is important, in this context, is that when nurses expand their role it is done so knowledgeably and with full understanding of the legal accountability of their practice.

The use of a protocol has been found to enable staff to identify (at the earliest opportunity) any patient capable of breathing spontaneously, to optimise extubation timing (to avoid both reintubation and overlong intubation), and to reduce weaning time. There is also evidence that the involvement of nurses and therapists in this process is beneficial.

'Available data suggest that not only are nurses and respiratory therapists able to wean patients from mechanical ventilation using protocols, but their participation seems essential for this process to occur in a timely manner' (Kollef et al., 1997).

Useful protocols aim to safely and efficiently liberate patients from mechanical ventilation by reducing unnecessary or harmful variations in approach. Ely et al. (2001) produced some evidencebased practice guidelines specifically for the design and implementation of weaning protocols. They made some key recommendations, which have informed the development of our Network Weaning Protocol:

* Protocols should be used to wean patients from mechanical ventilation;

* Non-medical health care practitioners should be involved in the development and utilisation of weaning protocols;

* Protocols should be developed using an evidence-based approach by a multidisciplinary team;

* Protocols should be implemented using effective behaviour changing strategies such as interactive education, opinion leaders, reminders, audit and feedback.

\section{THE NETWORK PROTOCOL}

Wherever possible, our protocol is based on an established evidence-base. However, there was insufficient evidence available for all steps in the protocol. When it was not possible to draw on published evidence, agreement was reached by professional consensus of the group members; in consultation with nursing, medical and physiotherapy colleagues. As noted above, the protocol was based on the earlier work of Lowe et al. (2001), which was then adapted to meet the needs of several ICUs.

The purpose of the protocol is to enable nurses at all levels to successfully wean the majority of intensive care patients. As with all protocols, it is not suitable for some patients, such as those with complex needs. The protocol should therefore be regarded as a guideline for practice rather than a strict set of rules. However, all decisions made to deviate from the protocol must be properly documented in the nursing and medical notes.

The complete process of weaning a patient from mechanical ventilation - which is covered in the protocol - comprises four stages:

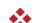

Assessment of the patient's readiness to commence weaning

* The process of incrementally reducing the patient's mechanical ventilatory support;

* Extubation;

* Post-extubation monitoring.

These stages are outlined in Figure 1. 


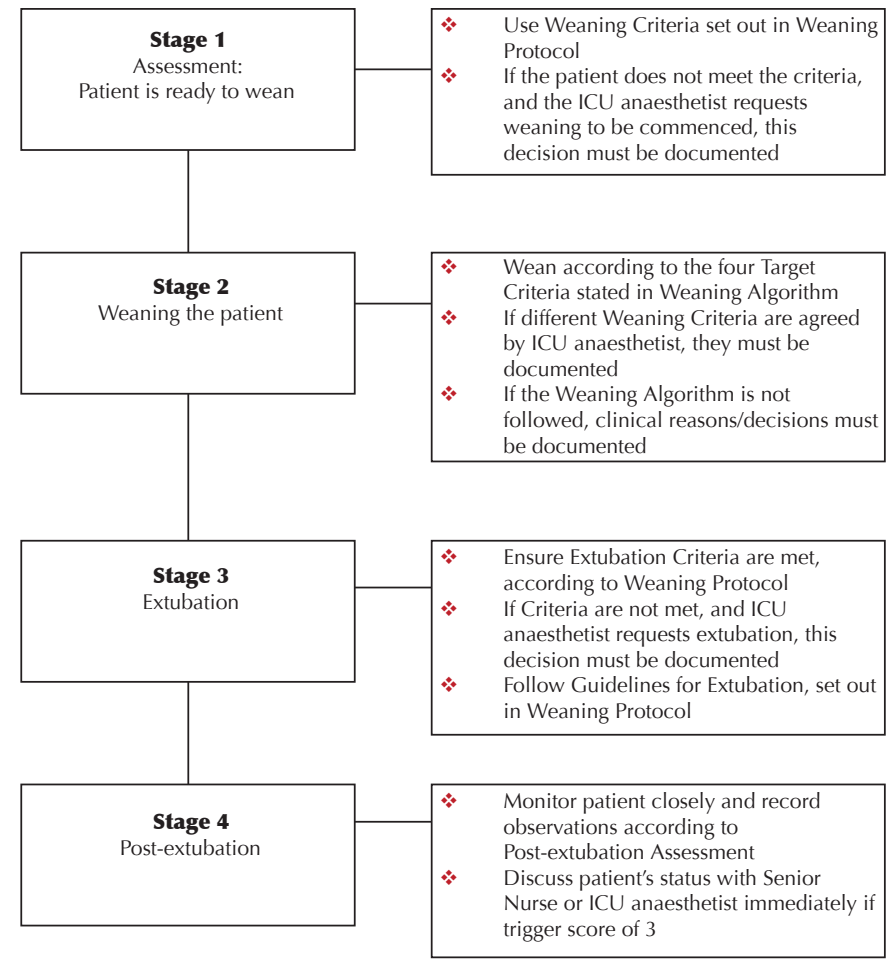

Figure 1. Network Weaning Protocol process diagram

\section{STAGE 1. ASSESSMENT OF THE PATIENT'S READINESS TO COMMENCE WEANING}

The decision as to when and how the weaning process should be initiated has historically been primarily one of individual clinical judgement. However, there is a growing body of evidence that suggests a structured approach to weaning patients from mechanical ventilation using protocols is more effective and efficient than relying on clinical judgement alone (Wood et al., 1995; Kollef et al., 1997; Horst et al., 1998; Marelich et al., 2000).

Weaning patients from mechanical ventilation is the process of gradually liberating them from artificial ventilatory support and allowing the resumption of spontaneous breathing (Henneman et al., 2001). This involves two main actions:

* Withdrawal of mechanical ventilatory support;

* Removal of the endotracheal tube.

Weaning a patient from the mechanical ventilator is one of the most challenging and rewarding aspects of care. The process should be managed safely, systematically and accurately. Successful weaning of patients from a mechanical ventilator requires careful physiological assessment of the patient's conscious level, psychological status, metabolic function, effects of drugs, cardiovascular performance, lung mechanics, pulmonary gas exchange and ventilatory function, and nutritional status.

\section{Criteria for Weaning}

The Network Weaning Protocol sets out a series of parameters to be met before weaning from ventilation is commenced. These are detailed in Figure 2. All criteria should be met before weaning. In some exceptional cases, medical colleagues may decide that is appropriate to commence weaning outside these criteria. Any such decision must be properly documented in the nursing and medical notes.

The purpose of establishing these criteria is primarily to ensure the patient's safety and secondarily to ensure that the patient is in an optimal physical state in preparation for the weaning process.

* The patient's underlying disease process is resolving.

* The patient's temperature is $36-38^{\circ} \mathrm{C}$ and the patient is perfused adequately.

* The patient's systolic blood pressure (BP) is $>90 \mathrm{mmHg}$ and mean arterial pressure (MAP) $>60 \mathrm{mmHg}$ with minimal or no inotropic support.

If the patient still requires inotropes or a higher MAP or a higher systolic BP weaning should be discussed with the ICU anaesthetist. (This must be recorded in the patient's notes.)

* The patient has satisfactory arterial blood gases: $\mathrm{PaCO}_{2}<7 \mathrm{kPa}$ and $\mathrm{PaO}_{2}>10 \mathrm{kPa}$ on $\mathrm{FiO}_{2}<0.6$ unless different values are agreed by the anaesthetist. (This must be recorded in the patient's notes.)

* The patient's respiratory rate is $<30$ breaths per minute and peak airway pressure $<30 \mathrm{cmH}_{2} \mathrm{O}$ AND PEEP $<8 \mathrm{CmH}_{2} \mathrm{O}$

* The patient has no severe electrolyte imbalance.

* The patient has no severe metabolic imbalance: base excess is between +5 to -5 .

* The patient has no significant bleeding/clotting problems.

* There are no neuromuscular blocking agents in progress and all effects have worn off.

* There is no significant respiratory muscle weakness.

* There is no sedation in progress, or if required, minimal sedation to maintain patient safety.

* There is no/minimal abdominal distension.

* There are no neurological contraindications to weaning.

Figure 2. Criteria for commencement of weaning

\section{STAGE 2. THE PROCESS OF INCREMENTALLY REDUCING THE PATIENT'S MECHANICAL VENTILATORY SUPPORT}

Psychological support and effective communication are key factors that contribute to successful weaning (Oztekin, 2001). In this respect, fully informing the patient of his/her progress, clear identification of weaning goals, and encouragement and praise are crucial.

Once the patient has met the criteria to commence weaning, the process of incremental reduction of mechanical ventilatory support can commence. The first principle that should be followed is that only one incremental change should be made at any given time, for example an incremental reduction in fractional inspired oxygen $\left(\mathrm{FiO}_{2}\right)$. This is so that the effects of changing individual parameters are assessable by observation of the patient's status. If more than one change is made at one time, this is not possible. The second principle is that if an incremental change is not tolerated it should be reversed.

The Network Weaning Protocol Weaning Process Algorithm (see Figure 3 ) identifies clearly each step in the weaning process. 


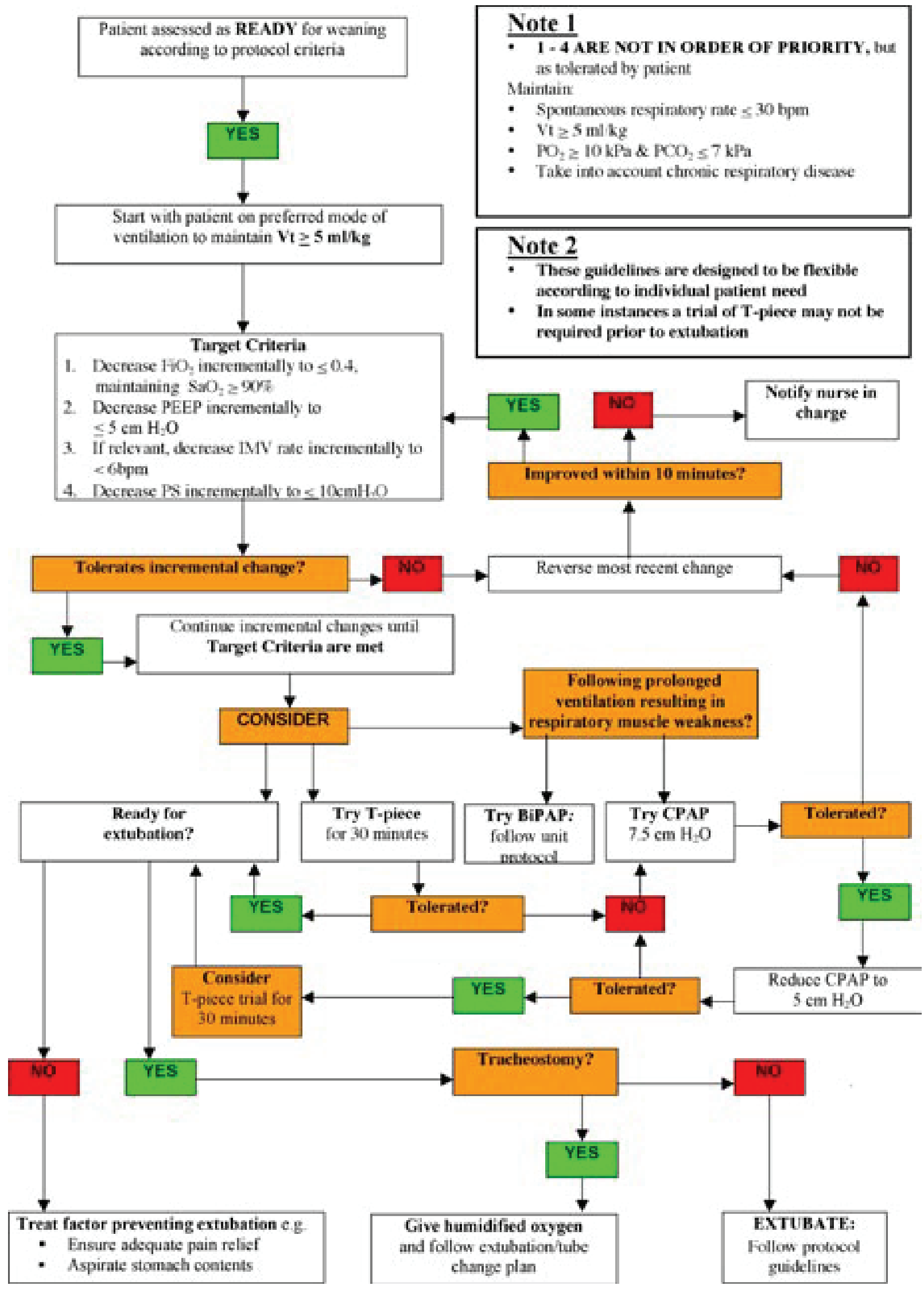

Figure 3. Weaning process algorithm 


\section{Target criteria}

The weaning process algorithm (Figure 3) sets out four target criteria based on the currently available evidence-base:

* Decrease $\mathrm{FiO}_{2}$ incrementally to $<0.4$;

* Decrease PEEP incrementally to $<5 \mathrm{cmH}_{2} \mathrm{O}$;

* If relevant, decrease IMV rate incrementally to $<6$ breaths per minute;

* Decrease pressure support to $<10 \mathrm{cmH}_{2} \mathrm{O}$.

It is important to note that the target criteria are not stated in order of priority, and the patient's response and tolerance will dictate progression of weaning towards these targets. Furthermore, it is important to recognise that the algorithm provides a guideline that is appropriate for most, but not all, patients. In addition, it is noted that not all ICUs use the same ventilators, and that intensive care clinicians will have different preferences for certain modes of ventilation. The algorithm has been designed to take account of local preferences. Particular consideration should be given to the setting of appropriate target criteria and ventilation modes for patients with chronic respiratory disease and those who have been ventilated for extensive periods.

If at any time during the weaning process a nurse is concerned that the patient is not responding appropriately to the incremental changes, their status and progress should be discussed with a senior nursing or medical colleague. Any deviations from the protocol should be recorded appropriately in the nursing and/or medical notes, with a clear explanation of the clinical reasons for doing so. Legal issues are discussed in more detail below.

\section{STAGE 3. EXTUBATION}

\section{Ready for extubation?}

When the target criteria have been achieved, a clinical decision must be made about the readiness of the patient for extubation. To ensure that patients have the best chance of successful extubation, a further assessment is advocated: a T-piece trial.

Prior to extubation patients should undergo a T-piece trial of 30 minutes' duration (Esteban et al., 1995). If this is successful, that is if the patient is able to breathe normally without distress, then s/he can be extubated. In some instances a T-piece trial may not be required, for example young, fit patients, ventilated for relatively short periods. If the clinical decision not to use a T-piece trial is made, the reasons should be documented in the nursing notes.

When a patient has respiratory muscle weakness, has been ventilated for a prolonged period and/or has chronic respiratory disease, it is advisable to support their breathing with continuous positive airway pressure (CPAP) before proceeding to a T-piece trial. Normally, after the target criteria have been met, CPAP should be commenced at $7.5 \mathrm{cmH}_{2} \mathrm{O}$. If this level is tolerated, it should then be reduced to $5 \mathrm{cmH}_{2} \mathrm{O}$. If this is tolerated, a T-piece trial can commence. If a clinical decision is made to use different levels of CPAP than those noted above and/or a decision is made not to use a T-piece trial, the reasons should be documented in the nursing notes.

Some ICUs prefer to wean patients using bi-phasic positive airway pressure (BiPAP) ventilation. Where this is the case, that unit's BiPAP policy/protocol should be followed. However, there are some basic principles that should be addressed:

* Initial settings should mirror the last settings on the ventilator. For example, if pressure support settings were set at $10 \mathrm{cmH}_{2} \mathrm{O}$ with positive end expiratory pressure
(PEEP) of $5 \mathrm{cmH}_{2} \mathrm{O}$, then inspiratory positive airway pressure (IPAP) should be set at $15 \mathrm{cmH}_{2} \mathrm{O}$ and expiratory positive airway pressure (EPAP) should be set at $5 \mathrm{cmH}_{2} \mathrm{O}$;

* $\quad$ IPAP - EPAP = pressure support;

* If support needs to be increased to achieve a $\mathrm{PaO}_{2}$ of $10 \mathrm{kPa}$, or if there is evidence of an increase in the patient's work of breathing, then the patient should be re-established on pressure support ventilation.

Oxygen flow through the BiPAP machine should be set initially at the rate of $10 \mathrm{l} / \mathrm{min}$, and should be reduced incrementally by $2 \mathrm{l} / \mathrm{min}$ while maintaining the patient's $\mathrm{SaO}_{2}$ at $>90 \%$, until the optimal level is reached.

\section{The extubation process}

A successful extubation is a well-planned process. There are two basic goals:

* $\quad$ Ensure the safety of the patient;

* Ensure the comfort of the patient.

Some patients may have a tracheostomy tube inserted. In such cases immediate extubation is rarely appropriate. Under these circumstances, the appropriate ICU policy/protocol for the management of tracheostomy tube extubation, wound dressing and/or permanent tracheostomy tube placement should be followed.

\section{Extubation criteria}

To ensure the patient's safety and to assess their readiness for extubation, a set of criteria must be achieved (see Figure 4). The Network Weaning Protocol provides a form for this purpose. If the criteria are not met, the patient should be reassessed again later. All criteria must be met for the patient to be assessed as ready for extubation. If the criteria are fulfilled, the nurse in charge and/or ICU anaesthetist should be informed. The patient may then be extubated, according to the ICU policy.

There are some exceptions to the above. The patient should be extubated with the ICU anaesthetist's approval/presence under the following circumstances:

* Any patient who does not fulfil weaning/extubation criteria but is felt to be ready for extubation;

* If, for clinical reasons, the anaesthetist wishes to keep the patient intubated despite fulfilling the criteria;

* Difficult intubations (grade III - IV): advice should be taken from the ICU anaesthetist, who should be present at extubation and may wish to extubate the patient him/herself;

* $\quad$ Other patients: it is not appropriate to use the criteria for patients with a history of significant lung disease, spinal patients who may require a separate protocol, or burn injured patients who may require frequent trips to theatre or may have inhalation injury. Advice should be sought from the ICU anaesthetist/consultant on an individual basis.

When decisions about extubation are made that deviate from the protocol, as with all other stages in the weaning process, the reasons for the decision and who made it should be recorded in the nursing and/or medical notes. The Network Weaning Protocol provides a form for this purpose. 
1. The patient is cardiovascularly stable and has: Systolic BP $>90 \mathrm{mmHg}$ AND MAP $>60 \mathrm{mmHg}$

AND is on minimal or no inotropic support

2. The patient has satisfactory blood gases:

$\mathrm{PaCO} 2<7 \mathrm{kPa}$

AND $\mathrm{PaO}_{2}>10 \mathrm{kPa}$

AND $\mathrm{SaO}_{2}>90 \%$ on $\mathrm{FiO}_{2}<0.4$

3. The patient's breathing is stable and has: (If relevant) an IMV respiratory rate of $<6 \mathrm{bpm}$ AND a SPONTANEOUS respiratory rate of $>8 \&<$ 30bpm

AND a SPONTANEOUS tidal volume $>5 \mathrm{mls} / \mathrm{kg}$

AND PEEP $<5 \mathrm{cmH}_{2} \mathrm{O}$

AND Pressure Support $<10 \mathrm{cmH}_{2} \mathrm{O}$

4. The patient's nasogastric tube is:

aspirated prior to extubation

OR if fine bore tube in situ, feeding has been stopped for 4 hours

5. The patient is able to cough adequately, clear secretions and breathe deeply

6. The patient has adequate pain relief

Figure 4. Criteria for extubation

\section{Psychological preparation of the patient}

Prior to any extubation procedure, the patient should be informed fully of what to expect. Each part of the process should be explained, detailing the sensations the patient may experience. Medical terminology should be avoided and language appropriate to the patient's level of understanding should be used. The patient should be given the opportunity to seek clarification and ask questions. Remember that while extubation is a fairly routine intensive care practice, it is not routine for patients. They can become anxious because they do not know quite what to expect; breathing problems are frightening (Todres et al., 2000). The nurse's calm, reassuring presence is an important factor in ensuring a successful extubation.

\section{Physical preparation of the patient}

Prior to extubation, the patient should be prepared physically. In particular, if the patient is being fed enterally, using a fine-bore tube, the feed should be turned off four hours before extubation is planned. If an ordinary nasogastric tube is in place, it should be aspirated immediately prior to extubation.

To prepare the patient optimally for extubation, their air entry should be auscultated and chest physiotherapy given if indicated. If their chest is clear it will make the work of breathing much easier. Ideally the patient should be positioned in an upright position they find comfortable that does not restrict diaphragmatic excursion.

\section{Preparation of equipment}

Appropriate equipment should be prepared at the patient's bedside for two reasons:

* to extubate the patient;

* to re-intubate the patient in an emergency.

Careful preparation will help to ensure the patient's safety. The oxygen supply should be checked, and an oxygen mask and tubing should be prepared, using humidified oxygen, so that the patient can use it immediately following extubation. Suction equipment, including Yankauer and endotracheal suction catheters, should be close at hand at the patient's bed head. The suction should be checked and set at the appropriate level. A $10 \mathrm{ml}$ syringe (to deflate the endotracheal tube (ETT) cuff) and scissors (to cut the ETT tape) should be at hand and a disposable towel or kidney dish should be nearby (in which to place the old ETT). A bowl and tissues should be available for the patient.

All emergency intubation equipment should be brought to the patient's bedside, including at least three endotracheal tubes: one the same size, one smaller and one larger that that being used by the patient prior to extubation. The presence and function of all equipment required for emergency intubation must be checked.

Prior to extubation the nurse in charge and/or intensive care anaesthetist should be informed. Junior nurses should seek the assistance/supervision of a senior colleague.

\section{The extubation process}

Endotracheal suction should be performed prior to extubation. However, techniques vary and local ICU guidelines/procedures/ policies should be followed. Throughout the extubation procedure the patient's respiratory rate, arterial oxygen saturation, colour and work of breathing should be monitored closely. The ETT tape should be untied/cut and the cuff deflated. The patient should be warned that when the cuff is deflated mucous above the cuff may fall into the trachea making them want to cough. The ETT should be held securely during cuff deflation to avoid premature self-extubation. When the ETT is removed it should be withdrawn in an arc moving towards the patient's chest, and the patient should be encouraged to cough immediately afterwards. Additional suction may be required to clear the upper airway. Humidified oxygen, provided via facemask, should be given at or above the level delivered when ventilated.

\section{STAGE 4. POST-EXTUBATION MONITORING}

The period immediately following extubation is a critical time for the patient. As noted above, psychological support, feedback and praise are important nursing actions that affect the patient's response to extubation.

Without any mechanical ventilatory assistance, the work of breathing increases following extubation. It is therefore important to continuously observe the patient's status until they are stable.

Following extubation the patient is observed closely using the Network Weaning Protocol Post-extubation Assessment (see Figure 5). The assessment tool provides a framework for observing and recording the patient's status for the first seven hours following extubation: quarter hourly for one hour, half hourly for two hours, and four hourly thereafter as required. It enables assessment of the patient in three areas: respiratory, cardiovascular and neurological.

The physiological assessment is used as the basis of an early warning scoring system. A simple score is made of the patient's physiological status. If the patient scores three or more, their status should be discussed with a senior ICU nurse or ICU anaesthetist. When a patient 'triggers', any discussion/action should be recorded in the nursing notes. 


\begin{tabular}{|c|c|c|c|c|c|c|c|}
\hline SCORE & 3 & 2 & 1 & $\mathbf{0}$ & 1 & 2 & 3 \\
\hline \multicolumn{8}{|l|}{$\begin{array}{l}\text { Respiratory } \\
\text { Assessment }\end{array}$} \\
\hline $\begin{array}{l}\text { Respiratory } \\
\text { rate }\end{array}$ & & $<8$ & & $8-30$ & $31-35$ & $36-39$ & $>40$ \\
\hline $\begin{array}{l}\text { Use of accessory } \\
\text { muscles }\end{array}$ & & & & None & Mild & Moderate & Severe \\
\hline Breath sounds & Absent & & Reduced & $\begin{array}{c}\text { Normal/ } \\
\text { Equal }\end{array}$ & Added & Unequal & $\begin{array}{l}\text { Unequal + } \\
\text { added }\end{array}$ \\
\hline $\begin{array}{l}\text { Ability to cough } \\
\text { \& clear secretions }\end{array}$ & & & & Adequate & $\begin{array}{l}\text { Weak but } \\
\text { able }\end{array}$ & $\begin{array}{l}\text { Just } \\
\text { adequate }\end{array}$ & Unable \\
\hline \multicolumn{8}{|l|}{$\begin{array}{l}\text { Cardiovascular } \\
\text { Assessment }\end{array}$} \\
\hline Heart rate & & $<40$ & $40-50$ & $51-100$ & $101-110$ & $111-129$ & $>129$ \\
\hline Heart rhythm & & & & Normal & & Abnormal & \\
\hline $\begin{array}{l}\text { Blood pressure: } \\
\text { MAP }\end{array}$ & $<50$ & & $50-59$ & $60-90$ & $91-100$ & $101-110$ & $>110$ \\
\hline Skin condition & & & & Normal & Cool & & Clammy \\
\hline \multicolumn{8}{|l|}{$\begin{array}{l}\text { Neurological } \\
\text { Assessment }\end{array}$} \\
\hline Responsiveness & & & & Alert & Voice & Pain & Unresponsive \\
\hline Anxiety/agitation & & & & Absent & Mild & Moderate & Severe \\
\hline Confusion & & & & Absent & Mild & Moderate & Severe \\
\hline $\begin{array}{l}\text { Discomfort and/ } \\
\text { or pain }\end{array}$ & & & & None & Mild & Moderate & Severe \\
\hline
\end{tabular}

Figure 5. Post-extubation scoring system.

\section{LEGAL ISSUES AROUND NURSE-LED WEANING}

Protocols should not present rigid rules but rather should act as guides to patient care.

This means that there may be occasions when it is appropriate to deviate from the protocol. However, from a legal perspective it is important that any deviations from the weaning protocol must be properly documented, with a clear description of the decisionmaking process and identification by name of those involved. When a protocol is used in practice it becomes a legal document that sets the standard for practice. Where a NHS policy (such as a protocol) exists, the staff are legally covered to implement it.

The UK nurses' Professional Code of Conduct Clause 6 (Nursing and Midwifery Council, 2002) states clearly that nurses must maintain and improve professional knowledge and competence. This is an important principle that governs practice. With respect to nurse-led weaning, each professional nurse is responsible and accountable for ensuring that they possess adequate knowledge and experience to undertake the procedure. In this context, 'Duty of Care' is an important legal principle. A nurse, by virtue of the nurse/patient relationship, owes a duty of care to their patients. This is said to exist if it can be seen that one's actions are reasonably likely to cause harm to another person.

\section{AUDIT}

Audit is an improvement process that seeks to improve patient care and outcomes through systematic review of care against explicit 
criteria and the implementation of change (National Institute for Clinical Excellence, 2002). Changes, such as the implementation of a new protocol, can use the audit process to confirm improvement in health care delivery. Audit can also be used to monitor change. The analysis of data, collected during audit, is fed back into the system to bring about improvements.

With respect to the Network Weaning Protocol, audit is being used primarily to assess its applicability and user-friendliness. Information collected during the audit will enable adjustments to be made to the protocol.

Four ICUs have recently implemented the protocol. If it is successful, other ICUs within the Network may adopt it. The first six months of its use are being audited, the primary purpose of which is to identify whether or not the protocol is being used, and what adjustments might be made to improve it. Snapshot data are being collected from all four units on one day per week. On the audit day, data are collected at three different times: 08.00, 16.00 and 24.00 hours, for all patients. In addition to anonymised patient information, several questions are posed:

* Is the protocol being used?

* Is the patient being weaned?

* If the protocol is not being used, why not?

* If the protocol is being used, are there any problems? If so, what are they?

* If the patient is being weaned, or has successfully been weaned, were the criteria for commencement of weaning met?

The audit information is being collated centrally, and compliance with the protocol is being presented back to the units in the form of a weekly run chart (see example, Figure 6). This gives immediate feedback to the units about how well they are doing. It also develops a healthy level of competition between the units! Information is also being collected in relation to the length of time the patients are ventilated and how long the weaning process takes. When the data are analysed over a longer period (at least a year), it may be possible to demonstrate the effect of using the protocol.

The protocol will be evaluated at the end of six months, when a series of questions will be posed (see Figure 7).

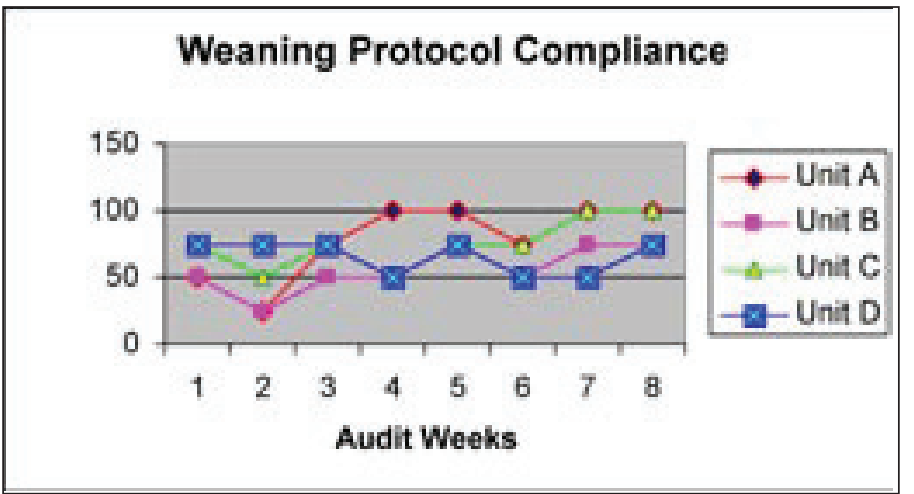

Figure 6. Example of a run chart illustrating compliance.

1. Have you used the weaning protocol?

2. Do you think the protocol is written in a clear and understandable way?

3. Using the protocol, are you clear about when to initiate the weaning process?

4. Do you think the weaning protocol is helpful?

5. Do you think the protocol enables junior nursing staff to make decisions about weaning?

6. Do you think junior nursing staff members were able to make weaning decisions using the protocol, rather than deferring to senior staff for 'permission'?

7. Do you think your medical colleagues are supportive of nurse-led weaning using the protocol?

8a. Do you think the protocol is suitable for most ICU patients?

8b. If $\mathrm{NO}$ to $8 \mathrm{a}$, why not?

9a. Is there anything additional that you would like to see included in the protocol?

9b. If YES to 9a, what?

10a. Do you think further improvements could be made to the protocol?

10b. If YES to $10 \mathrm{a}$, what?

11. What do you think is the most positive aspect of the protocol?

Figure 7. Protocol evaluation.

\section{CONCLUSIONS}

There is substantial evidence that adherence to a weaning protocol improves patient outcomes. It is of less significance which professional group leads the weaning process. However, it may be argued that since ICU nurses spend more time with the patient than any other professional group, they are in the best position to manage the weaning process. Because their close association with the patient means that they are more likely to 'know' the patient, they are arguably more able to be sensitive to the patient's progress and responses.

The development of a nursing protocol is a lengthy process that requires careful consideration. Each stage of the protocol must be sufficiently detailed so that practising nurses are not left uncertain about what should be done. An ambiguous protocol is a dangerous one.

Once a protocol is placed in the public domain it becomes a benchmark by which standards are measured. This raises important legal concerns. Although a protocol should not be considered as a rigid set of rules, any deviations from it should be properly documented for legal reasons.

The role of audit, when a new process is introduced into clinical practice, cannot be understated. An important improvement question to ask is, 'how will we know that a change is an improvement?' (Batalden \& Stoltz, 1993). At the end of the day this can be paraphrased as a very simple question: has the change made a positive difference to patients?

The Central Southern Critical Care Network Nurse-led Weaning Protocol is only one of many that are reported in the literature. We developed it for our local use, but we believe that it might be applied to many other ICUs. If any readers are interested in further information about the protocol, the authors would be delighted to correspond.

\section{REFERENCES}

Batalden PB, Stoltz PK. (1993) A framework for the continual improvement of health care: building and applying professional 
improvement knowledge to test changes in daily work. The

Joint Commission Journal on Quality Improvement 19 (10): 424-447.

Cronin S. (1997) Nursing care of clients with disorders of lung pleura.

Medical Surgical Nursing. Philadelphia, Saunders, pp1133-1187.

Department of Health. (1996) Research and Development: Towards an Evidence-Based Health Service. London, Department of Health.

Department of Health. (1997) The New NHS: Modern, Dependable. London, Department of Health.

Department of Health. (1998) A First Class Service. London, Department of Health.

Department of Health. (2000) Comprehensive Critical Care. London, Department of Health.

Ely EW, Meade MO, Haponik EF, Kollef MH, Cook DJ, Guyatt GH, Stoller JK. (2001) Mechanical ventilator weaning protocols driven by nonphysician health-care professionals: evidence-based clinical practice guidelines. Chest 120 (6 Suppl.): 454S-463S.

Esteban A, Alia I, Ibanez J, Benito S, Tobin MJ. (1994) Modes of mechanical ventilation and weaning. A national survey of Spanish hospitals. The Spanish Lung Failure Collaborative Group. Chest 106 (4): 1188-1193.

Esteban A, Frutos F, Tobin MJ, Alia I, Solsona JF, Valverdu I, Fernandez R, de la Cal MA, Benito S, Tomas R. (1995) A comparison of four methods of weaning patients from mechanical ventilation. New England Journal of Medicine 332 (6): 345-350.

Henneman E, Dracup K, Ganz T, Molayeme O, Cooper C. (2001) Effect of a collaborative weaning plan on patient outcome in the critical care setting. Critical Care Medicine 29 (2): 297-303.

Henneman E, Dracup K, Ganz T, Molayeme O, Cooper CB. (2002) Using a collaborative weaning plan to decrease duration of mechanical ventilation and length of stay in the intensive care unit for patients receiving long-term ventilation. American Journal of Critical Care 11 (2): 132-140.

Horst HM, Mouro D, Hall-Jenssens RA, Pamukov N. (1998) Decrease in ventilation time with a standardized weaning process. Archives of Surgery 133 (5): 483-488.

Keen A. (2000) Critical incident: reflection on the process of terminal weaning. British Journal of Nursing 9 (16): 1059-2031.

Knebel AR. (1991) Weaning from mechanical ventilation: current controversies. Heart and Lung 20 (4): 321-331.

Kollef MH, Shapiro SD, Silver P, St John RE, Prentice D, Sauer S, Ahrens TS, Shannon W, Baker-Clinkscale D. (1997) A randomized controlled trial of protocol-directed versus physician-directed weaning from mechanical ventilation. Critical Care Medicine 25 (4): 567-574.

Lowe F, Fulbrook P, Aldridge H, Fox S, Gillard J, O'Neill J, Papps L. (2001) Weaning from ventilation: a nurse-led protocol. Connect: Critical Care Nursing in Europe 1 (4): 124-133.

Mancebo J. (1996) Weaning from mechanical ventilation. European Respiratory Journal 9 (9): 1923-1931.

Marelich GP, Murin S, Battistella F, Inciardi J, Vierra T, Roby M. (2000) Protocol weaning of mechanical ventilation in medical and surgical patients by respiratory care practitioners and nurses: effect on weaning time and incidence of ventilator-associated pneumonia. Chest 118 (2): 459-467.

National Institute for Clinical Excellence. (2002) Principles for Best Practice in Clinical Audit. Oxford, Radcliffe Medical Press.

NHS Modernisation Agency. (2004) Critical care: a patient need not a place [Online]. Available at: http://www.modern.nhs.uk/scripts/default. asp?site_id=20 [Accessed June 2004].

Nursing and Midwifery Council. (2002) Code of Professional Conduct.
London, NMC

Oztekin D. (2001) Weaning from mechanical ventilation. Connect: Critical Care Nursing in Europe 1 (2): 52-58.

Scheinhorn DJ, Artinian BM, Catlin JL. (1994) Weaning from prolonged mechanical ventilation: the experience at a regional weaning center. Chest 105 (2): 534-539.

Todres L, Fulbrook P, Albarran J. (2000) On the receiving end: a hermeneutic-phenomenological analysis of a patient's struggle to cope while going through intensive care. Nursing in Critical Care 5 (6): 277-287.

United Kingdom Central Council for Nursing Midwifery and Health Visiting (UKCC). (1992) The Scope of Professional Practice. London, UKCC.

Vassilakopoulos T, Zakynthinos S, Roussos C. (1996) Respiratory muscles and weaning failure. European Respiratory Journal 9 (11): 2383-2400.

Wood G, MacLeod B, Moffatt S. (1995) Weaning from mechanical ventilation: physician-directed $\mathrm{Vs}$ a respiratory-therapist-directed protocol. Respiratory Care 40 (3): 219-224.

\section{FURTHER READING}

Blackwood B. (2003) Can protocolised-weaning developed in the United States transfer to the United Kingdom context: a discussion. Intensive \& Critical Care Nursing 19 (4): 215-25.

Bonell C (1999). Evidence-based nursing: a stereotyped view of quantitative and experimental research could work against professional autonomy and authority. Journal of Advanced Nursing 30 (1): 18-23.

Chan PK, Fischer S, Stewart TE, Hallett DC, Hynes-Gay P, Lapinsky SE, MacDonald R, Mehta S. (2001) Practising evidence-based medicine: the design and implementation of a multidisciplinary team-driven extubation protocol. Critical Care 5 (6): 349-354.

Crocker C. (2002) Nurse led weaning from ventilatory and respiratory support. Intensive \& Critical Care Nursing 18 (5): 272-279.

Croft B. (2002) Ventilator weaning protocols. [Online.] RT The Journal for Respiratory Care Practitioners August/September, available from http://www.rtmagazine.com/ [accessed May 2004].

Cronin S. (1997) Nursing care of clients with disorders of lung pleura. Medical Surgical Nursing. Philadelphia, Saunders, pp1133-1187.

Duane TM, Riblet JL, Golay D, Cole FJ Jr., Weireter LJ Jr., Britt LD. (2002) Protocol-driven ventilator management in a trauma intensive care unit population. Archives of Surgery 137 (11): 1223-1227.

Ely EW, Baker AM, Evans GW, Haponik EF. (1997) The prognostic significance of passing a daily screen of weaning parameters. Intensive Care Medicine 25: 581-587.

Ely EW, Bennett PA, Bowton DL, Murphy SM, Florance AM, Haponik EF. (1999) Large-scale implementation of a respiratory therapist-driven protocol for ventilator weaning. American Journal of Respiratory Critical Care Medicine 159 (2): 439-446.

Frutos-Vivar F, Esteban A. (2003) When to wean from a ventilator: an evidence-based strategy. Cleveland Clinical Journal of Medicine 70 (5): 389, 392-3, 397.

Grap MJ, Strickland D, Tormey L, Keane K, Lubin S, Emerson J, Winfield S, Dalby P, Townes R, Sessler CN. (2003) Collaborative practice: development, implementation and evaluation of a weaning protocol for patients receiving mechanical ventilation. American Journal of Critical Care 12 (5): 454-460.

Hill NS. (2001) Following protocol: weaning difficult-to-wean patients with chronic obstructive pulmonary disease. American Journal of Respiratory Critical Care Medicine 164 (2): 186-187.

Kollef MH, Horst HM, Prang L, Brock WA. (1998) Reducing the duration 
of mechanical ventilation: three examples of change in the intensive care unit. New Horizons 6 (1): 52-60.

Martensson I, Fridlund B. (2002) Factors influencing the patient during weaning from mechanical ventilation: a national survey. Intensive \& Critical Care Nursing 18 (4): 219-229.

Meade M, Guyatt G, Cook D, Griffith L, Sinuff T, Kergl C, Mancebo J, Esteban A, Epstein S. (2001) Predicting success in weaning from mechanical ventilation. Chest 120 (6 Suppl): 425S-437S.

Meade M, Guyatt G, Sinuff T, Griffith L, Hand L, Toprani G, Cook DJ. (2001) Trials comparing alternative weaning modes and discontinuation assessments. Chest 120 (6 Suppl): 400S-424S.

Perren A, Domenighetti G, Mauri S, Genini F, Vizzardi N. (2002) Protocol-directed weaning from mechanical ventilation: clinical outcome in patients randomized for a 30-min or 120-min trial with pressure support ventilation. Intensive Care Medicine 28 (8): 1 058-1063.

Price AM. (2001) Nurse-led weaning from mechanical ventilation: where's the evidence? Intensive \& Critical Care Nursing 17 (3): 167-176.

Saura P, Blanch L, Mestre J, Valles J, Artigas A, Fernandez R. (1996) Clinical consequences of the implementation of a weaning protocol. Intensive Care Medicine 22 (10): 1052-1056.

Scheinhorn DJ, Chao DC, Stearn-Hassenpflug M, Wallace WA. (2001) Outcomes in post-ICU mechanical ventilation: a therapist-implemented weaning protocol. Chest 119 (1): 236-242.

Smyrnios NA, Connolly A, Wilson MM, Curley FJ, French CT, Heard SO, Irwin RS (2002) Effects of a multifaceted, multidisciplinary, hospital-wide quality improvement program on weaning from mechanical ventilation. Critical Care Medicine 30 (6): 1224-1230.

Stoller JK, Mascha EJ, Kester L, Haney D. (1998) Randomized controlled trial of physician-directed versus respiratory therapy consult service-directed respiratory care to adult non-ICU inpatients. American Journal of Respiratory Critical Care Medicine 158 (4): 1068-1075. 